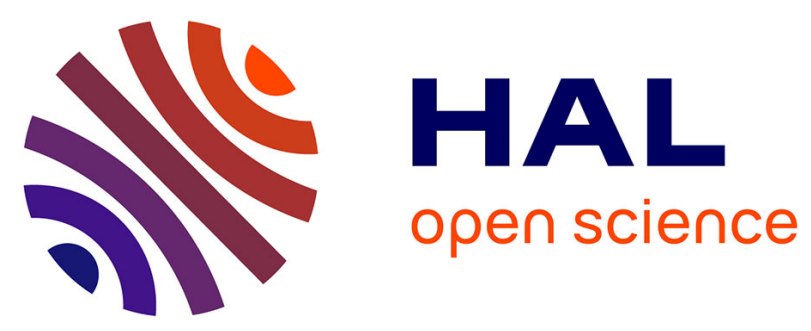

\title{
Comparing extraction, synergism and separation of lanthanoids using acidic and neutral compounds in chloroform and one ionic liquid: is the latter always "better"?
}

\author{
Maria Atanassova, Vanya Kurteva, Lubomir Lubenov, Isabelle Billard
}

\section{To cite this version:}

Maria Atanassova, Vanya Kurteva, Lubomir Lubenov, Isabelle Billard. Comparing extraction, synergism and separation of lanthanoids using acidic and neutral compounds in chloroform and one ionic liquid: is the latter always "better"?. RSC Advances, 2014, 4 (73), pp.38820-38829. 10.1039/c4ra04302b . hal-02271606

\section{HAL Id: hal-02271606 \\ https://hal.science/hal-02271606}

Submitted on 27 Aug 2019

HAL is a multi-disciplinary open access archive for the deposit and dissemination of scientific research documents, whether they are published or not. The documents may come from teaching and research institutions in France or abroad, or from public or private research centers.
L'archive ouverte pluridisciplinaire HAL, est destinée au dépôt et à la diffusion de documents scientifiques de niveau recherche, publiés ou non, émanant des établissements d'enseignement et de recherche français ou étrangers, des laboratoires publics ou privés. 


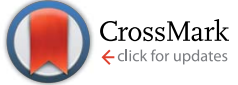

Cite this: RSC Adv., 2014, 4, 38820
Received 8th May 2014

Accepted 31st July 2014

DOI: $10.1039 / c 4 r a 04302 b$

www.rsc.org/advances

\section{Comparing extraction, synergism and separation of lanthanoids using acidic and neutral compounds in chloroform and one ionic liquid: is the latter always "better"?†}

\begin{abstract}
Maria Atanassova, ${ }^{\text {ac }}$ Vanya Kurteva, ${ }^{\mathrm{b}}$ Lubomir Lubenov $^{\mathrm{b}}$ and Isabelle Billard ${ }^{\mathrm{c}}$
The complexation properties of a pyrazolone derivative, 3-methyl-1-phenyl-4-(4-trifluoromethylbenzoyl)pyrazol-5-one ( $\mathrm{HL})$, in chloroform were examined and it was found that it possesses improved complexation ability in comparison with 4-benzoyl, 4-(4-methylbenzoyl) and 4-(4-fluorobenzoyl) derivatives. Mixed ligand chelate extractions of trivalent lanthanoids ( $\mathrm{La}, \mathrm{Nd}, \mathrm{Eu}, \mathrm{Ho}$ and $\mathrm{Lu}$ ) with $\mathrm{HL}$ and 5,11,17,23-tetra-tert-butyl-25,26,27-tris(dimethylphosphinoylpropoxy)-28-hydroxy-calix[4]arene (S1) or 5,11,17,23-tetra-tert-butyl-25,27-bis(dimethylphosphinoylpropoxy)-26,28-dihydroxy-calix[4]arene (S2) as synergistic agents were also carried out in chloride medium at constant ionic strength $\mu=0.1$ and $\mathrm{CHCl}_{3}$ as organic phase. The interactions between the extractants in deuterochloroform were studied by ${ }^{1} \mathrm{H}$, ${ }^{13} \mathrm{C}$, and ${ }^{31} \mathrm{P}$ NMR. The composition of the extracted species was established as $\mathrm{LnL} \cdot \mathrm{HL}\left(\mathrm{L}^{-}\right.$represents

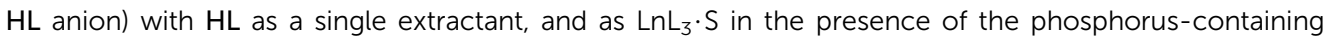
calix[4]arene. On the basis of the experimental data, the values of the equilibrium constants were calculated. The influence of the number of $\mathrm{P}=\mathrm{O}$ groups of tert-butyl-calix[4]arene on the extraction process was discussed. The synergistic enhancement and separation factors between metals were evaluated. Finally, the extraction of $\mathrm{La}(\mathrm{III})$ and $\mathrm{Eu}(\mathrm{III})$ ions was performed by using an ionic liquid, 1-butyl3-methylimidazolium-bis(trifluoromethanesulfonyl)imide, as a solvent and varying the type of ligands. By comparison to $\mathrm{CHCl}_{3}$, the ionic liquid offers increased distribution ratios, at the expense of a levelling off of the separation factors. Reasons for such a phenomenon are discussed.
\end{abstract}

\section{Introduction}

As part of our systematic work on the synergistic solvent extraction of lanthanoids, ${ }^{1-8}$ we performed comparative studies aiming at (i) improving the extraction ability of $\beta$-diketone compounds by increasing their acidity, (ii) studying the dependence of the extraction properties on the number of the ligating groups on a calixarene scaffold and finally, (iii) understanding the role of the solvent for extraction, separation and synergism by comparing a traditional molecular solvent, chloroform, and one ionic liquid, namely 1-methyl-3-

${ }^{a}$ Department of General and Inorganic Chemistry, University of Chemical Technology and Metallurgy, 8 Kliment Ohridski blvd., 1756 Sofia, Bulgaria. E-mail: ma@uctm. edu; Fax: +35928163415

${ }^{b}$ Institute of Organic Chemistry with Centre of Phytochemistry, Bulgarian Academy of Sciences, Block 9, Acad. G. Bonchev street, BG 1113, Sofia, Bulgaria

'Institut Pluridisciplinaire Hubert Curien, Rue du Loess 23, 67037 Strasbourg Cedex, France

$\uparrow$ Electronic supplementary information (ESI) available: Experimental details and characterization of $\mathbf{H L}$, Fig. S1-S6 and extraction of $\operatorname{Ln}(\mathrm{III})$ ions with chelating extractant, HL only (Fig. S7), Fig. S8-S18 concerning the extractants interaction as well as Fig. S19-21 presenting the extraction results in IL. See DOI: 10.1039/c4ra04302b butylimidazolium bis(trifluoromethanesulfonyl)imide, thereafter denoted as $\left[\mathrm{C}_{1} \mathrm{C}_{4} \mathrm{im}\right]\left[\mathrm{Tf}_{2} \mathrm{~N}\right]$. It is our opinion that the wellassessed strategy based on the individual independent improvements of the extractants used in a synergistic system, which has proven to be quite efficient in molecular solvents, ${ }^{\mathbf{1 - 8}}$ may find some limitations in ionic liquids (ILs). Ionic liquids are studied for an increasing number of applications in various aspects of chemistry and of course liquid-liquid extraction of rare earths and other metals. ${ }^{9-11}$ It is now acknowledged that the nanodomains existing in the bulk of ILs and their supramolecular organization lead to very specific solvating properties, thus of great impact onto Ln and An complexation ${ }^{\mathbf{1 2}}$ and, consequently, on extraction from aqueous towards IL phases. Actually, many papers have evidenced tremendous favorable changes, in terms of extraction efficiency, for a variety of systems, when passing from a molecular solvent to an ionic liquid. Another important general result is that the extraction model is, most of the time, very different in ILs as compared to molecular solvents. ${ }^{13}$ In this respect, it could be envisioned that "good recipes" in molecular solvents may not be fully applicable in ILs. It is thus important to investigate the possible changes induced by replacing molecular solvents by ILs on the 
synergism phenomenon and pre-organization effect, comparing step by step extraction, separation and then, synergism. In fact, although many synergistic systems have been investigated in traditional molecular solvents, where the solvent nature has proven to be part of the parameters for getting high efficiencies, few papers have dealt so far with the question of synergism in ionic liquids. ${ }^{\mathbf{1 4 - 1 7}}$ In particular, calixarenes are widely studied for their extracting abilities and the benefit they offer in terms of pre-organization of the complexing pattern in molecular solvents but studies on these questions in IL-based extraction systems are scarce. ${ }^{18,19}$ To our knowledge, only a handful of publications on synergism in ILs is available. For example in $\mathrm{Am}^{3+} / \mathrm{HNO}_{3} / /(\mathrm{TBP}+\mathrm{CMPO}) /\left[\mathrm{C}_{1} \mathrm{C}_{4} \mathrm{im}\right]\left[\mathrm{Tf}_{2} \mathrm{~N}\right]$ (TBP: tri$n$-butyl phosphate), ${ }^{14}$ much less CMPO ( $N, N$-diisobutylcarbamoylmethyl)octylphosphine oxide than in the equivalent dodecane system is requested, with distribution ratios above 2 $\times 10^{4}$ or equal to 16 in $\left[\mathrm{C}_{1} \mathrm{C}_{4} \mathrm{im}\right]\left[\mathrm{Tf}_{2} \mathrm{~N}\right]$ and dodecane respectively. Hirayama et al. ${ }^{16}$ investigated the system HTTA-18C6$\left[\mathrm{C}_{1} \mathrm{C}_{4} \mathrm{im}\right]\left[\mathrm{Tf}_{2} \mathrm{~N}\right]$ for selective extraction of $\mathrm{La}, \mathrm{Eu}$ and $\mathrm{Lu}$ focusing on the size-fitting effect. The La(III) was efficiently extracted as $\mathrm{La}(\mathrm{TTA})_{2}(18 \mathrm{C} 6)^{+}$by the cation-exchange process (TTA: 2-thenoyltrifluoroacetone, 18C6: 18-crown-6), but Eu and Lu experience small synergistic effect. The environmentally benign $\mathrm{Sr}^{2+}$ separation system obtained by the combination of neutralneutral extractants was developed by Stepinski et al. ${ }^{17}$ Addition of TBP markedly increased the extraction of $\mathrm{Sr}^{2+}$ into $\left[\mathrm{C}_{5} \mathrm{C}_{1} \mathrm{im}\right]\left[\mathrm{Tf}_{2} \mathrm{~N}\right]$ by DCH18C6 (dicyclohexyl-18-crown-6) and the synergism depends on the alkyl chain length of the IL-cation.

In order to get a deeper insight into the role of ILs, we therefore focused our efforts on a newly synthesized acidic pyrazolone derivative as extractant, HL, for which we report herein synthesis and extraction properties. This compound is used either alone or in conjunction with two partially phosphorilated at the narrow rim tert-butyl-calix[4]arenes calixarenebased compounds, $\mathbf{S 1}$ and $\mathbf{S 2}$, both in chloroform and in IL towards 5 trivalent lanthanoid ions. The reasons that prompted us to choose these various compounds are detailed below. First, 4-acylpyrazol-5-ones are among the most widely exploited O-donors in coordination chemistry ${ }^{20-23}$ due to their lower $\mathrm{p} K_{\mathrm{a}}$ values (2.56-4.26) in comparison with conventional $\beta$-diketones, such as acetylacetone $\left(\mathrm{p} K_{\mathrm{a}}=9.0\right)$ and thenoyltrifluoroacetone $\left(\mathrm{p} K_{\mathrm{a}}=6.25\right)$. The nature of the substituent in the fourth position of the pyrazolone ring causes significant variations in the electronic, steric, and solubility parameters of the ligand, thereby affecting complexation and extraction of metal ions including 4f- and 5f-elements. ${ }^{1,22}$ While 4-benzoyl, 4-(4methylbenzoyl) and 4-(4-fluorobenzoyl) derivatives are slightly studied, 4-(4-trifluoromethylbenzoyl) pyrazolone has not been examined, ${ }^{\mathbf{1 , 2 1}}$ so that the chemical challenge was one of the experimental and synthetic incentive of this work.

Second, calixarenes are a versatile class of supramolecular compounds widely exploited as molecular platforms for the introduction of specific ligating arms in a reorganized pattern suitable for metal ions complexation. ${ }^{\mathbf{1 - 8 , 2 4 - 2 6}}$ Depending on the nature of the ligating groups, on the dimension of the macrocyclic scaffold and on the hydrophobicity, calixarenes have shown immense selectivity in the separation of alkaline and alkaline earth ions, ${ }^{27}$ heavy metals ${ }^{28}$ and f-elements. ${ }^{1,29}$ The latter and the tunable shape of the molecules make them ideal candidates for building blocks and molecular scaffolds in the design of new and more sophisticated ligands. There are two basic features to modify these unique three-dimensional structures with almost unlimited derivatization abilities: introduction of variable substituents and additional functional groups both at the lower ( $\mathrm{OH}$ side) and upper (alkyl branch side) rims. As is well-known, compounds possessing $\mathrm{P}=\mathrm{O}$ group like phosphonates, phosphines and phosphine oxide derivatives, have shown high affinity for f-elements. Combined with calixarene extracting properties, ligands with phosphorus containing pendant arms at the lower rim have led to a substantial enhancement of the extraction effectiveness and selectivity in molecular solvents. ${ }^{\mathbf{1 , 3 0 , 3 1}}$ Some have proven to be better extractants for lanthanoids than TOPO (tri- $n$-octylphosphine oxide) or CMPO used in the nuclear waste management. ${ }^{31}$ It has been noted by Ludwig et $a .^{32}$ that the cavity size, the position and kind of donor groups as well as the ligand hydrophobicity have a pronounced impact on the extraction ability and selectivity. The intra-group separation efficiencies of the partial-cone isomers of calix[4]arene substituted by phosphoryl and amide groups have been evaluated in a competitive extraction process of 11 rareearth metal ions by Yaftian et $a .^{33}$ It is noteworthy that the more effective extraction has been accompanied with better selectivity. ${ }^{31}$ The authors established also that the distribution ratios increase with the polarity of the molecular solvents in the order chloroform < dichloromethane < 1,2-dichloroethane < nitrobenzene. ${ }^{31,33}$ Contrary to the studies on the efficiency of calixarenes as single extractant, the records on their efficacy as synergistic agents in the field of solvent extraction are quite limited..$^{2-6,34}$ This gave us therefore another impulse for this work.

\section{Experimental}

\section{Reagents}

All reagents were purchased from Merck and Fluka and were used without any further purification. Fluka silica gel/TLC-cards 60778 with fluorescent indicator $254 \mathrm{~nm}$ were used for TLC chromatography. The melting point of pyrazolone was determined in a capillary tube on SRS MPA100 OptiMelt (Sunnyvale, CA, USA) automated melting point system. The NMR spectra were recorded on a Bruker Avance II +600 spectrometer (Rheinstetten, Germany) at $25{ }^{\circ} \mathrm{C}$; the chemical shifts were quoted in $\mathrm{ppm}$ in $\delta$-values against tetramethylsilane (TMS) as an internal standard or against $\mathrm{H}_{3} \mathrm{PO}_{4}$ as external standard in ${ }^{31} \mathrm{P}$ spectra; the coupling constants were calculated in $\mathrm{Hz}$.

The pyrazolone derivative, 3-methyl-1-phenyl-4-(4trifluoromethylbenzoyl)-pyrazol-5-one $(\mathbf{H L}),{ }^{35}$ was obtained according to an adapted literature procedure ${ }^{36}$ in excellent yield (Scheme 1). The experimental details and full characterization of the ligand are given in the ESI together with the original 1D and 2D NMR spectra (Fig. S1-S6†).

The lower rim partially substituted calix[4]arenes, 5,11,17,23tetra-tert-butyl-25,26,27-tris(dimethylphosphinoylpropoxy)-28hydroxy-calix[4]arene (S1) and 5,11,17,23-tetra-tert-butyl-25,27bis(dimethylphosphinoylpropoxy)-26,28-dihydroxy-calix[4]arene 


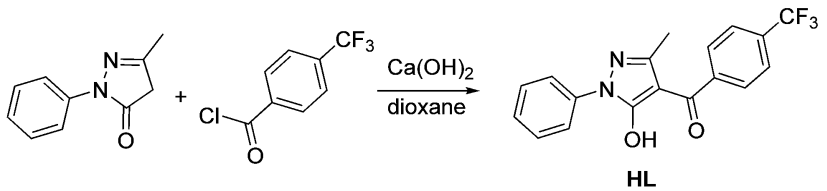

Scheme 1 Synthesis of 3-methyl-1-phenyl-4-(4-trifluoromethylbenzoyl)-pyrazol-5-one (HL).
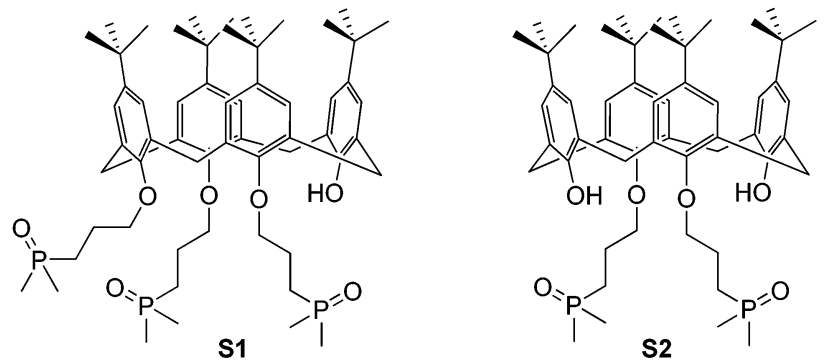

Fig. 1 Structural formulas of ligands S1 and S2.

(S2), shown on Fig. 1, were synthesized by one-pot alkylation of commercially available tert-butylcalix[4]arene as already published by us. ${ }^{37}$

The solvents were $\mathrm{CHCl}_{3}$ (Merck, p.a.) and 1-butyl-3-methyl imidazolium-bis(trifluoromethanesulfonyl)imide (Solvionic, France). Stock solutions of metals at concentration equal to 2.5 $\times 10^{-3} \mathrm{~mol} \mathrm{dm}^{-3}$ were prepared from their oxides (Fluka, puriss) by dissolving in concentrated hydrochloric acid and diluting with distilled water to the required volume. Arsenazo III (Fluka) was of analytical grade purity as were the other reagents used.

\section{Solvent extraction procedure}

The experiments were carried out using $10 \mathrm{~cm}^{3}$ volumes of aqueous and organic phases. The samples were shaken mechanically (Orbital Shaker OS-20, Boeco, Germany, $120 \mathrm{rpm}$ ) for 45 minutes at room temperature $\left(22 \pm 2{ }^{\circ} \mathrm{C}\right)$ which was sufficient to reach equilibrium. ${ }^{\mathbf{1 - 8}}$ After the separation of the phases, the metal concentration in the aqueous phase was determined spectophotochemically (S-20 Spectrophotometer Boeco, Germany) using Arsenazo III. ${ }^{38}$ The concentration of the metal ion in the organic phase was calculated by subtraction of the determined amount in the aqueous phase from the total amount present. The acidity of the aqueous phase was measured by a digital $\mathrm{pH}$ meter ( $\mathrm{pH} 211$ HANNA, USA) with an accuracy of $0.01 \mathrm{pH}$ units. The ionic strength was maintained at $0.1 \mathrm{M}$ with $(\mathrm{Na}, \mathrm{H}) \mathrm{Cl}$. The initial concentration of the metals was $2.5 \times 10^{-4} \mathrm{~mol} \mathrm{dm}{ }^{-3}$ in all experiments.

In order to determine metal distribution ratios using ionic liquid as organic media for $\mathrm{La}(\mathrm{III})$ and $\mathrm{Eu}(\mathrm{III})$ extraction, $2.5 \mathrm{~cm}^{3}$ of organic and aqueous phases of specific composition identical with those used when $\mathrm{CHCl}_{3}$ was employed were stirred for 60 minutes at room temperature $\left(22 \pm 2{ }^{\circ} \mathrm{C}\right)$, phases were separated and metal content was determined.

\section{Results and discussion}

\section{Extraction, synergism and separation in $\mathrm{CHCl}_{3}$}

Solvent extraction of $\mathrm{Ln}$ (III) ions with HL, S1 or S2 alone. Based on the preceding results, ${ }^{\mathbf{1 , 4}, 39}$ the extraction equilibria of lanthanoids with 4-acylpyrazolones can be described by the equation:

$$
\mathrm{Ln}^{3+}{ }_{(\mathrm{aq})}+4 \mathbf{H L}_{(\mathrm{o})} \leftrightarrow \mathrm{LnL}_{3} \cdot \mathbf{H L}_{(\mathrm{o})}+3 \mathrm{H}^{+}(\mathrm{aq})
$$

where $\mathrm{Ln}^{3+}$ denotes lanthanoid and the subscripts "aq" and "o" indicate the species in the aqueous and organic phase.

The extraction constant, $K_{\mathrm{L}}$, is defined as,

$$
K_{\mathrm{L}}=\frac{\left[\mathrm{LnL}_{3} \cdot \mathrm{HL}\right]_{(\mathrm{o})}\left[\mathrm{H}^{+}\right]_{(\mathrm{aq})}{ }^{3}}{\left[\mathrm{Ln}^{3+}\right]_{(\mathrm{aq})}[\mathrm{HL}]_{(\mathrm{o})}{ }^{4}}=D_{\mathrm{L}} \frac{\left[\mathrm{H}^{+}\right]_{(\mathrm{aq})}{ }^{3}}{[\mathrm{HL}]_{(\mathrm{o})}{ }^{4}}
$$

where $D_{\mathrm{L}}$ is the lanthanoid distribution ratio. As seen from online resource Fig. $\mathrm{S} 7 \dagger$ the plots of $\log D_{\mathrm{L}} v s . \mathrm{pH}$ and $\log [\mathbf{H L}]$ are linear, with slopes very close to 3 and 4 , in accordance with eqn (1).

The equilibrium constants for the extraction of lanthanoids with 3-methyl-1-phenyl-4-(4-trifluoromethylbenzoyl)-pyrazol-5one were calculated on the basis of eqn (3) and summarized in Table 1.

$$
\log K_{\mathrm{L}}=\log D_{\mathrm{L}}-3 \mathrm{pH}-4 \log [\mathbf{H L}]
$$

The values of $\log K_{\mathrm{L}}$ are approximately 1.50, 1.20 and 0.9 logarithmic units higher than those obtained with 3-methyl-4(4-methylbenzoyl)-1-phenyl-pyrazol-5-one (HPMMBP), 3methyl-4-benzoyl-1-phenyl-pyrazol-5-one (HP) and 3-methyl-1phenyl-4-(4-trifluoromethylbenzoyl)-pyrazol-5-one (HPMFBP) respectively. This difference is due to the fact that $\mathbf{H L}$ is a slightly stronger acid $\left(\mathrm{p} K_{\mathrm{a}}=3.40(\right.$ ref. 23$\left.)\right)$ than HPMMBP $\left(\mathrm{p} K_{\mathrm{a}}\right.$ $=4.02), \operatorname{HP}\left(\mathrm{p} K_{\mathrm{a}}=3.92\right)$ and $\operatorname{HPMFBP}\left(\mathrm{p} K_{\mathrm{a}}=3.52\right) .{ }^{1,21}$ The acidity of the extracting agent is increased by the electronwithdrawing effect of the fluorinated group, and the extracting agent can be used to extract metal ion from more acidic aqueous solutions, the equilibrium values increase as the $\mathrm{p} K_{\mathrm{a}}$ value decreases.

By contrast, the experimental data showed that the lanthanoid ions extraction with 5,11,17,23-tetra-tert-butyl-calix[4]arenes with two and three dimethylphosphinoylpropoxy ligating groups at the narrow rim used alone is negligible under the experimental conditions of the present study in $\mathrm{CHCl}_{3}$. The latter is probably due to deactivation of the basic phosphoryl groups by $\mathrm{H}$-bonding with the solvent. ${ }^{40,41}$

Interactions between $\mathrm{HL}$ and $\mathrm{S} 1$ or S2. An important problem for systems containing mixtures of extractants used for solvent extraction of metals is their possible interaction. ${ }^{1,7}$ The unfavorable role of the extractant interaction was noted by Zhang. ${ }^{\mathbf{4 2}} 45$ years ago Marcus and Kertes ${ }^{\mathbf{4 3}}$ have also pointed out that the interaction between an acidic and a neutral extractant is a reason for the destruction of the synergism. The interactions between acidic (HL) and neutral (S) extractant applied in the present study were examined by NMR experiments in the 
Table 1 Values of the equilibrium constants $K_{\mathrm{L}}, K_{\mathrm{L}, \mathrm{S}}$ and $\beta_{\mathrm{L}, \mathrm{S}}$, synergistic coefficients and separation factors for lanthanoids extraction with mixtures $\mathrm{HL}-\mathrm{S}^{a}$

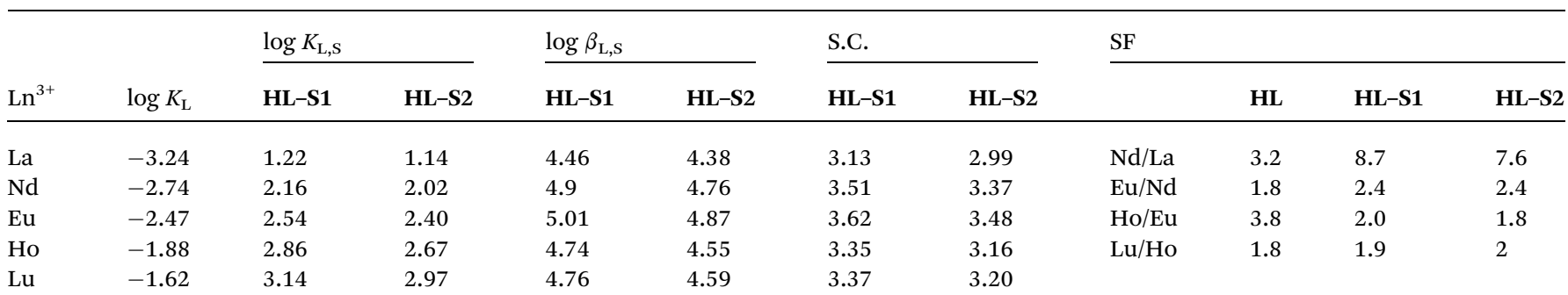

${ }^{a}$ The values of the equilibrium constants are calculated on the basis of the 35 experimental points; statistical confidence is $95 \%$ and standard deviation is less than \pm 0.05 . S.C.: $\mathrm{pH}=2.20,[\mathbf{H L}]=1.5 \times 10^{-2} \mathrm{~mol} \mathrm{dm}^{-3},[\mathrm{~S}]=7 \times 10^{-4} \mathrm{~mol} \mathrm{dm}^{-3}$.

Table $2{ }^{31} \mathrm{P}$ chemical shifts of calixarenes (S) and S: HL mixtures

\begin{tabular}{|c|c|c|c|c|c|c|c|}
\hline \multirow[b]{2}{*}{${ }^{31} \mathrm{P}$} & \multirow{2}{*}{$\frac{\mathrm{S}}{\delta}$} & \multicolumn{2}{|c|}{ S : HL $3: 1$} & \multicolumn{2}{|c|}{ S : HL $1: 1$} & \multicolumn{2}{|c|}{ S: HL $1: 3$} \\
\hline & & $\delta$ & $\Delta \delta$ & $\delta$ & $\Delta \delta$ & $\delta$ & $\Delta \delta$ \\
\hline $2 / 3 \mathbf{S} \mathbf{1}^{a}$ & 43.75 & 43.88 & +0.13 & 44.04 & +0.29 & 44.33 & +0.58 \\
\hline $1 / 3 \mathbf{S} \mathbf{1}^{a}$ & 45.13 & 45.34 & +0.21 & 45.60 & +0.47 & 45.92 & +0.79 \\
\hline S2 & 43.56 & 43.63 & +0.07 & 43.80 & +0.34 & 44.19 & +0.63 \\
\hline
\end{tabular}

${ }^{a}$ Calixarene $\mathbf{S 1}$ shows a single intensity signal for ${ }^{31} \mathrm{P}$ of the substituent at 26 position and a double intensity one for those at 25 and 27 positions; indicated as $1 / 3 \mathbf{S 1}$ and $2 / 3 \mathbf{S 1}$, respectively.

same solvent used in the extraction. Slight upfielding of the signals for methyl and methylene groups of the alkyl substituents of calixarenes with the addition of HL were detected both in proton and carbon spectra (Fig. S8-S11†), while phosphorus signals were downfielded, as shown on Table 2 and Fig. S12. $\dagger$ The values of the shifting of the signals increase with the increase of the HL content, which is an indication that the effects are dependent on the extractants' ratio. Negligible chemical shift changes were registered in the spectra of $\mathbf{H L}$ upon mixing with S. However, the methyl protons give broad signals (Fig. S8 and S9†) and the methyl group and quaternary carbon at the $3^{\text {rd }}$ position do not appear in the carbon spectra even in S : HL 1 : 3 mixtures with both calixarenes (Fig. S10 and $\mathrm{S} 11 \dagger)$. This pattern is compatible with slow exchange between two sites, resulting from the rotation of the acyl group, i.e. between molecules with $\mathrm{C}=\mathrm{O}$ in the $\mathrm{CH}_{3}-3$ and $\mathrm{OH}$ side, which influenced mainly the methyl group at position 3 and quaternary $\mathrm{C}_{\mathrm{q}}-3$ atom due to the carbonyl anisotropy. The latter shows that the strong $\mathrm{H}$-bond between hydroxyl proton and carbonyl oxygen in HL molecule is partially destroyed due to interaction with $\mathrm{P}=\mathrm{O}$ of the calixarene molecule. The existence of two exchangeable sites is an indication that the interactions between the components of the extracting systems are localized on the pyrazolone hydroxyl group and do not involve the carbonyl function.

Synergistic solvent extraction of $\operatorname{Ln}(\mathrm{III})$ ions with mixtures of HL and S1 or S2. The experimental data for the synergistic solvent extraction of the lanthanoid(III) ions with mixtures of $\mathbf{H L}$ and $\mathbf{S 1}$ or $\mathbf{S} 2$ are given in Fig. 2-4. The plots of $\log D_{\mathrm{L}, \mathrm{S}}$ versus $\mathrm{pH}$ and $\log [\mathbf{H L}]$ are linear with slopes close to three and the plots of $\log D_{\mathrm{L}, \mathrm{S}}$ vs. $\log [\mathrm{S}]$ with slopes close to one. Therefore, in the presence of phosphorus-containing calix[4]arenes, the lanthanoid extraction can be expressed by the equation:

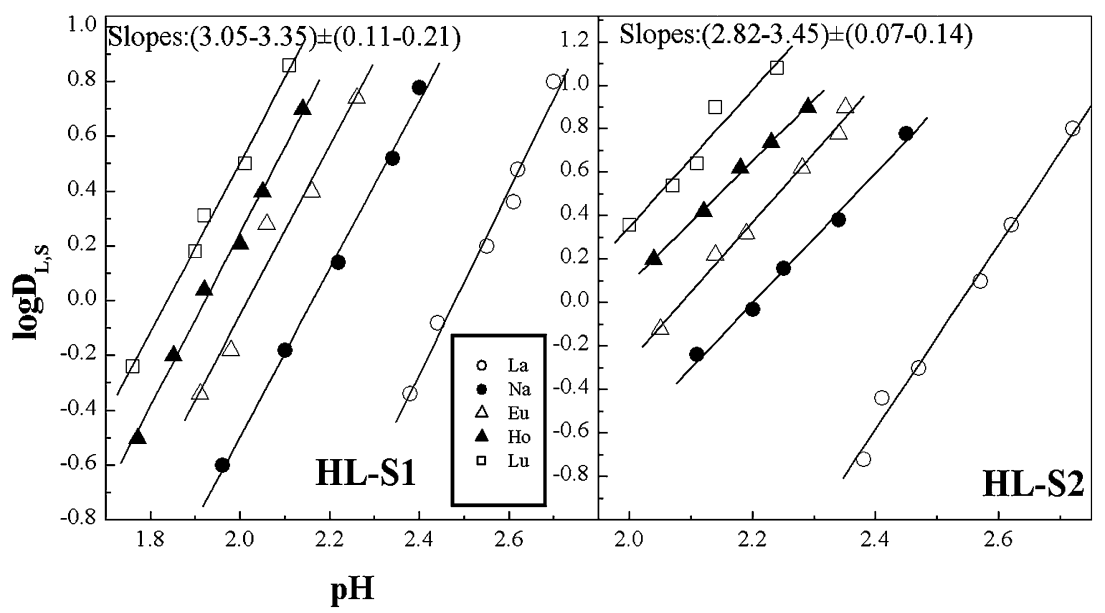

Fig. $2 \log D_{\mathrm{L}, \mathrm{S}}$ vS. $\mathrm{pH}$ for the extraction of lanthanoid(III) ions with mixtures $\mathrm{HL}-\mathrm{S}$ at $[\mathrm{HL}]=1.5 \times 10^{-2} \mathrm{~mol} \mathrm{dm}^{-3}$ and $[\mathrm{S}]=7 \times 10^{-4} \mathrm{~mol} \mathrm{dm} \mathrm{m}^{-3}$ in $\mathrm{CHCl}_{3}$. 


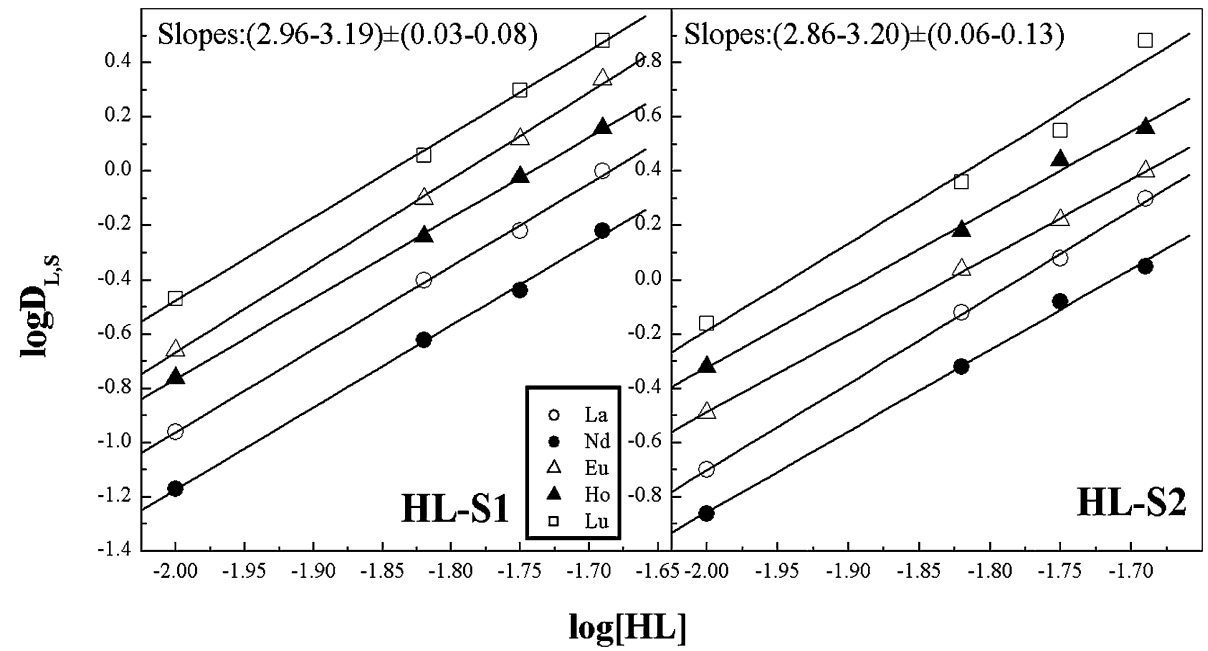

Fig. $3 \log D_{L, S}$ VS. $\log [\mathrm{HL}]$ for the extraction of lanthanoid(III) ions with mixtures $\mathrm{HL}-\mathrm{S}$ at $[\mathrm{S}]=7 \times 10^{-4} \mathrm{~mol} \mathrm{dm}^{-3}$ in $\mathrm{CHCl}_{3}$. $\mathrm{HL}-\mathrm{S} 1: \mathrm{La}, \mathrm{pH}=2.35$; $\mathrm{Nd}, \mathrm{pH}=1.95 ; \mathrm{Eu}, \mathrm{pH}=2.00 ; \mathrm{Ho}, \mathrm{pH}=1.85 ; \mathrm{Lu}, \mathrm{pH}=1.85$. $\mathrm{HL}-\mathrm{S} 2: \mathrm{La}, \mathrm{pH}=2.50 ; \mathrm{Nd}, \mathrm{pH}=2.10 ; \mathrm{Eu}, \mathrm{pH}=2.10 ; \mathrm{Ho}, \mathrm{pH}=2.05 ; \mathrm{Lu}, \mathrm{pH}=2.00$.

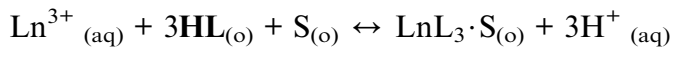

The observed extraction model in the two used systems is identical. This shows that the lanthanoid extraction behavior was not influenced qualitatively by the number of dimethylphosphinoylpropoxy groups of calix[4]arene.

Similar mixed complexes $\mathrm{LnL}_{3} \cdot \mathrm{S}$ with involvement of one molecule of tetraphosphorylated at the narrow rim calix[4]arene in the extracted species, have been found in our previous studies..$^{\mathbf{1 , 3 , 4 , 6}}$

Taking into account that the transfer of pyrazolones ${ }^{\mathbf{2 1}}$ and the calixarene ${ }^{37}$ to the aqueous phase is very low, the overall equilibrium constant values $K_{\mathrm{L}, \mathrm{S}}$ can be determined by the equation:

$$
\log K_{\mathrm{L}, \mathrm{S}}=\log D_{\mathrm{L}, \mathrm{S}}-3 \log [\mathbf{H L}]-\log [\mathrm{S}]-3 \mathrm{pH}
$$

The formation of mixed complexes in the organic phase can be described by the following equation:

$$
\mathrm{LnL}_{3} \cdot \mathbf{H L}_{(\mathrm{o})}+\mathrm{S}_{(\mathrm{o})} \leftrightarrow \mathrm{LnL}_{3} \cdot \mathrm{S}_{(\mathrm{o})}+\mathbf{H L}
$$

The equilibrium constant $\beta_{\mathrm{L}, \mathrm{S}}$ for the organic phase synergistic reaction can be determined as:

$$
\log \beta_{\mathrm{L}, \mathrm{S}}=\log K_{\mathrm{L}, \mathrm{S}}-\log K_{\mathrm{L}}
$$

The values of the equilibrium constants $K_{\mathrm{L}, \mathrm{S}}$ and $\beta_{\mathrm{L}, \mathrm{S}}$ calculated from the experimental data are given in Table 1. The equilibrium constants are based on the assumption that the activity coefficients of the species do not change significantly

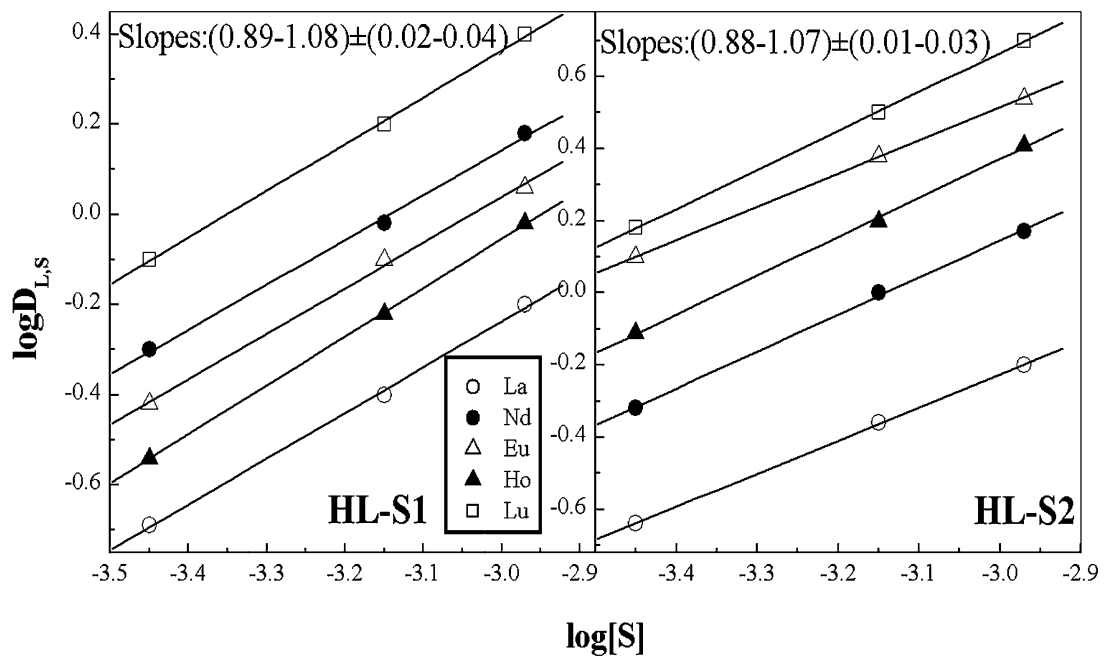

Fig. $4 \log D_{\mathrm{L}, \mathrm{S}}$ vs. $\log [\mathrm{S}]$ for the extraction of lanthanoid(II) ions with mixtures $\mathrm{HL}-\mathrm{S}$ at $[\mathrm{HL}]=1.5 \times 10^{-2} \mathrm{~mol} \mathrm{dm}^{-3}$ in $\mathrm{CHCl}$. $\mathrm{HL}-\mathrm{S} 1: \mathrm{La}$, $\mathrm{pH}=$ 2.35; $\mathrm{Nd}, \mathrm{pH}=2.15 ; \mathrm{Eu}, \mathrm{pH}=2.00 ; \mathrm{Ho}, \mathrm{pH}=1.85 ; \mathrm{Lu}, \mathrm{pH}=1.90$. $\mathrm{HL}-\mathrm{S} 2: \mathrm{La}, \mathrm{pH}=2.45 ; \mathrm{Nd}, \mathrm{pH}=2.20 ; \mathrm{Eu}, \mathrm{pH}=2.20 ; \mathrm{Ho}, \mathrm{pH}=2.05 ; \mathrm{Lu}, \mathrm{pH}=$ 2.05 . 
under the experimental conditions i.e. they are concentration constants. The data presented in Table 1 show that the addition of S1 and S2 to the system Ln(III)-HL leads to a very large increase of the values of $K_{\mathrm{L}, \mathrm{S}}$ in comparison with those of $K_{\mathrm{L}}$ (4-5 orders of magnitude). The values of $\log K_{\mathrm{L}}$ and $\log K_{\mathrm{L}, \mathrm{S}}$ increase from $\mathrm{La}$ to $\mathrm{Lu}$, in agreement with the increasing charge density resulting from the lanthanoid contraction. The obtained $\log K_{\mathrm{L}, \mathrm{S}}$ with $\mathbf{S} \mathbf{1}$ are a little bit larger i.e. this agent exhibits better extraction properties and is more efficient than the corresponding S2 homologue compound. So, the number of the flexible narrow rim ligating groups, two and three, of the studied $p$-t-butylcalix[4]arenes causes quantitative changes in the synergistic solvent extraction of lanthanoids. The crucial role of the phosphoryl groups in the complexation of the rare earth ions was reported by Yaftian et al. ${ }^{33}$ This finding was corroborated by extraction studies with narrow rim substituted cone-calix[4]arenes containing two, three and four phosphoryl groups. The authors unambiguously established that a higher number of $-\mathrm{CH}_{2} \mathrm{P}(\mathrm{O}) \mathrm{Ph}_{2}$ groups tethered to a calix[4]platform favors the extraction of rare-earth metal ions. Another example of the functional group affinity, that calixarenes bearing one to three CMPO residues are less efficient extractants than the tetraCMPO calix[4]arene was also reported by Arnaud-Neu et al. ${ }^{\mathbf{3 0}}$

The synergistic enhancement obtained for the combination of two extractants can be evaluated by calculating the synergistic coefficients (SC) as: $\mathrm{SC}=\log \left[\left(D_{1,2}\right) /\left(D_{1}+D_{2}\right)\right]$ where $D_{1,2}, D_{1}$ and $D_{2}$ denote the distribution ratio of a metal ion using mixture of extractants $\left(D_{1,2}\right)$ and using the same extractants separately $\left(D_{1}\right.$ and $D_{2}$ ). The calculated values of the synergistic coefficients of the lanthanoid ions are given in Table 1. It is seen that all Ln(III) ions are extracted synergistically ( $\mathrm{SC}>0$ ). The addition of the two calix[4]arenes to the chelating extractant improves the extraction efficiency of $\operatorname{Ln}(\mathrm{III})$ ions and produces large synergistic effects up to $10^{3}$. S1 produces a more significant effect on the lanthanoids extraction and highly enhances it. The synergistic enhancement did not show any great change from La to Lu. The obtained SC values for Ln(III) ions in the present study are in the most cases a little bit higher than those when phosphorus containing calix[4]arene with four $\mathrm{P}=\mathrm{O}$ donor groups was used as synergistic agent in combination with HP, HPMMBP and HPMFBP ${ }^{\mathbf{1 , 4}}$ but $\mathbf{H L}$ is a stronger acidic chelating extractant.

Separation factors and abilities for $\mathbf{H L}$ and $\mathbf{H L}-\mathbf{S}$. When the metal ions form complexes of the same type (as in the present case), the separation of the lanthanoids using HL alone and HL-S mixtures can be assessed by the separation factors (SF) calculated as a ratio of the equilibrium constants $K_{\mathrm{L}}$ or $K_{\mathrm{L}, \mathrm{S}}$ of two lanthanoids (the heavier and the lighter one). Their values are also given in Table 1. It is seen that the SF obtained for the extraction of the $\mathrm{Ho} / \mathrm{Eu}$ pair with $\mathrm{HL}$ alone is approximately 2 times higher than those obtained for the synergistic extraction. It is generally believed that the synergistic extraction makes the separation of metals worse, compared with the extraction with a chelating ligand only., ${ }^{3,4}$ The obtained SF values are higher for the two synergistic systems used especially for the first pair, $\mathrm{Nd} /$ La. It should also be noted that a loss of separation selectivity is observed across the $4 \mathrm{f}$-series due to the cation radii decrease of approximately $20 \%$ from La to Lu. If both the extraction efficiency and the separation selectivity are taken into account, the synergistic combination of HL-S1 shows some advantage under comparable conditions. The comparison of the results show that the SFs of the pairs $\mathrm{Ho} / \mathrm{Eu}$ and Lu/Ho obtained in this study are similar to those found for the synergistic extraction of lanthanoids with the chelating extractants HPMFBP and HPMMBP in combination with 5,11,17,23-tetra-tert-butyl-25,26,27,28-tetrakis(dimethylphosphinoylmethoxy)calix[4]arene. ${ }^{1}$ Concerning the SF values, a moderate selectivity has been noticed with the present systems as compared to the case when similar extraction systems were used. ${ }^{6}$

\section{Extraction, synergism and separation in IL}

Preliminary experiments. Actually, pure IL phases of the imidazolium family are known to extract various metal ions. For example, the extraction behavior of Ce(Iv) along with that of Th(IV) and $\operatorname{Ln}(\mathrm{III})(\mathrm{Ln}=\mathrm{Ce}, \mathrm{Gd}$ and $\mathrm{Yb})$ by pure $\left[\mathrm{C}_{8} \mathrm{C}_{1} \mathrm{im}\right]\left[\mathrm{PF}_{6}\right]$ was investigated by $\mathrm{Li}$ et al. $^{\mathbf{4 4}}$ The authors established that $\left[\mathrm{C}_{8} \mathrm{C}_{1} \mathrm{im}\right]\left[\mathrm{PF}_{6}\right]$ alone showed good extraction ability for $\mathrm{Ce}(\mathrm{Iv})$, while it was inefficient for Th(IV) and $\operatorname{Ln}(\mathrm{III})$. Other examples from the imidazolium family can be found for $\mathrm{Pu}(\mathrm{Iv})^{\mathbf{4 5 , 4 6}}$ (for a review of this effect for $\mathrm{An}$ and $\mathrm{Ln}$, see ref. 11) and $\mathrm{Au}(\mathrm{III})^{47}$ while several d-block metals can be extracted with phosphonium ILs. ${ }^{48}$ This prompted us to check the possibility of $\mathrm{Eu}$ (III) quantitative extraction by $\left[\mathrm{C}_{1} \mathrm{C}_{4} \mathrm{im}\right]\left[\mathrm{Tf}_{2} \mathrm{~N}\right]$. The results indicate that this pure IL does not act as an extracting phase at the investigated $\mathrm{pH}$ value (2.67). This result is in line with previous ones obtained for ILs of the same family under various acidic conditions (in particular, $1 \mathrm{M}$ nitric acid). ${ }^{49}$ As a consequence, all extraction results obtained in the present study in IL phase are due to the presence of the extracting agents.

In a second step, the solubility of the compounds in IL was investigated. As previously reported,$^{50}$ neutral extractants are readily soluble in imidazolium-based ILs, however acidic extractants showed poor solubility and this greatly affects the extraction performance. $\mathbf{S 1}$ and $\mathbf{S 2}$ have excellent solubility in $\left[\mathrm{C}_{1} \mathrm{C}_{4} \mathrm{im}\right]\left[\mathrm{Tf}_{2} \mathrm{~N}\right]$, while HL needs time to be fully soluble (ex. 8.6 $\times 10^{-3} \mathrm{~mol} \mathrm{dm}^{-3}, 1-2 \mathrm{~h}$ ).

Third, the interactions between the ionic liquid (IL) and the components of the extracting systems were studied. Such interactions are not expected due to the absence of functional groups in IL. Only weak H-bonding of IL nitrogen with HL OH can be assumed. Therefore, their interactions were studied at different molar ratios by proton and carbon NMR experiments. All samples were prepared separately by using pure dry compounds dissolved in deuterated solvents. Deuterobenzene was chosen due to its inert nature. As seen on Fig. S15 and S16, $\dagger$ the proton and carbon resonances of both IL and HL have the same values in the spectra of the individual compounds and in those of their $1: 1$ mixture. The latter is an indication that no interactions between the ionic liquid (IL) and acidic extractant (HL) occur in the inert solvent benzene- $d_{6}$. The interactions were further studied in deuteroacetonitrile (Fig. S17 and S18 $\dagger$ ) and in deuterochloroform (Fig. S19-S24 $\dagger$ ), H-bond acceptor and donor, respectively, and the same pattern was observed. 
Extraction by individual compounds HL, S1 and S2. In order to investigate the role of ionic liquid on the extraction process, a set of experiments was performed under conditions of the aqueous phase comparable with those carried out in $\mathrm{CHCl}_{3}$. The distinct extraction behavior of the corresponding systems towards La was described in Fig. S25 and S26† and towards La and Eu in Fig. S27. $\dagger$ The present results show great change in the extraction percentage at approximately 1.7 times lower concentration of the chelating extractant (HL), Fig. S27 $\dagger$ and the stoichiometry of the $\mathrm{La}(\mathrm{III})-\mathbf{H L}$ complex in IL and $\mathrm{CHCl}_{3}$ is different. From the obtained results (Fig. S25†) the extraction process of $\mathrm{La}$ (III) with $\mathrm{HL}$ in $\left[\mathrm{C}_{1} \mathrm{C}_{4} \mathrm{im}\right]\left[\mathrm{Tf}_{2} \mathrm{~N}\right]$ can be described by the equation:

$$
\mathrm{Ln}^{3+}{ }_{(\mathrm{aq})}+3 \mathrm{HL}_{(\mathrm{o})} \leftrightarrow \mathrm{LnL}_{3(\mathrm{o})}+3 \mathrm{H}^{+}{ }_{(\mathrm{aq})}
$$

The equilibrium constant was calculated and presented in Table 3:

$$
\log K_{\mathrm{L}}=\log D_{\mathrm{L}}-3 \mathrm{pH}-3 \log [\mathbf{H L}]
$$

In ILs, it has been shown that lanthanoids maintain the usual coordination number they display in molecular solvents. ${ }^{\mathbf{1 2}}$ Consequently, in eqn (8) above, the complex $\mathrm{LnL}_{3}$ has an unsaturated first coordination sphere. In an IL solution, the completion of the coordination sphere can be achieved either through binding with the $\mathrm{Tf}_{2} \mathrm{~N}^{-}$anions or by water molecules that are known to transfer to the IL phase: $c a .12000$ ppm under such chemical conditions. ${ }^{49}$ Furthermore, it has been shown by EXAFS and Molecular Dynamics that in IL solutions, Eu(III) (and other metal ions) display in fact two successive well-defined coordination spheres, of alternate charge, that closest to the metal centre being either composed of $\mathrm{Tf}_{2} \mathrm{~N}^{-}$or $\mathrm{C}_{1} \mathrm{C}_{4} \mathrm{im}^{+}$ions, depending on the neat charge of the metal entity. ${ }^{51,52}$ Finally, it has been shown that $\mathrm{Tf}_{2} \mathrm{~N}^{-}$is one of the weakly coordinating anions ever, and does not compete favourably with $\mathrm{H}_{2} \mathrm{O}$ for $\mathrm{Eu}(\mathrm{III})$ coordination sphere in many cases. ${ }^{\mathbf{1 0}}$

Higher extraction efficiency of various extractants in ILs as compared to traditional molecular solvents is a common feature and different stoichiometries of the extracted species are usually found, ${ }^{\mathbf{9 1 1}}$ but not always. ${ }^{\mathbf{5 1}}$ The HL behavior is perfectly in line with these general results. Albinsson has concluded that in the organic phase $\left(\mathrm{C}_{6} \mathrm{H}_{6}\right)$ at least two complexes exist, $\mathrm{LnAa}_{3}$ and the self-adduct $\mathrm{LnAa}_{3} \cdot \mathrm{HAa}$ as well as for the lower lanthanoids (especially La) a second self-adduct, $\mathrm{LnAa}_{3}(\mathrm{HAa})_{2}$ was supposed to be extracted with acatylacetone. $^{53,54}$ In addition, Binnemans also noted that at low HTTA

Table 3 Values of the equilibrium constants $K_{\mathrm{L}}, K_{\mathrm{S}}$ and $K_{\mathrm{L}, \mathrm{S}}$ and synergistic coefficient for $\mathrm{La}(\mathrm{III})$ extraction with $\mathrm{HL}, \mathrm{S} 1$ and $\mathrm{HL}-\mathrm{S} 1$ mixture

\begin{tabular}{lllll}
\hline $\log K_{\mathrm{L}}$ & $\log K_{\mathrm{S}}$ & $\log K_{\mathrm{L}, \mathrm{S}}$ & $\log \beta_{\mathrm{L}, \mathrm{S}}$ & $\mathrm{SC}$ \\
\hline-2.33 & 3.30 & 3.34 & 5.67 & 2.52
\end{tabular}

concentration neutral $\left[\operatorname{Ln}(\mathrm{TTA})_{3}\left(\mathrm{H}_{2} \mathrm{O}\right)_{x}\right]$ complexes are extracted into the IL phase. ${ }^{\mathbf{1 0}}$ In the IL phase, only deprotonated moieties are binding to the metallic center (eqn (8)). This is of course ascribable to changes in the coordination sphere in the IL as compared to $\mathrm{CHCl}_{3}$, linked to changes in the solvent properties.

S1 used alone in $\left[\mathrm{C}_{1} \mathrm{C}_{4} \mathrm{im}\right]\left[\mathrm{Tf}_{2} \mathrm{~N}\right]$ also shows a considerable effect to extract lanthanoids: as it is seen from Fig. S27, $\uparrow$ S1 acts as an excellent ligand for $4 \mathrm{f}$-ions. In $\left[\mathrm{C}_{1} \mathrm{C}_{4} \mathrm{im}\right]\left[\mathrm{Tf}_{2} \mathrm{~N}\right]$, a slope of 1 obtained from the plot indicates that one molecule of $\mathbf{S 1}$ is involved in the extraction step, Fig. S26. $\uparrow$ The calculated value of $\log K_{\mathrm{S}}$ as $\log K_{\mathrm{S}}=\log D_{\mathrm{S}}-\log [\mathbf{S} 1]$ is also presented in Table 3. In line with other results for different Eu extraction systems in ionic liquids ${ }^{\mathbf{4 9 , 5 5}}$ we therefore propose that La extraction by $\mathbf{S 1}$ alone in $\left[\mathrm{C}_{1} \mathrm{C}_{4} \mathrm{im}\right]\left[\mathrm{Tf}_{2} \mathrm{~N}\right]$ proceeds through cationic exchange according to the following equilibrium:

$$
\mathrm{Ln}^{3+}{ }_{(\mathrm{aq})}+\mathrm{S1}_{(\mathrm{o})}+3 \mathrm{C}_{1} \mathrm{C}_{4} \mathrm{im}^{+}{ }_{(\mathrm{o})} \leftrightarrow[\mathrm{LnS1}]^{3+}{ }_{(\mathrm{o})}+3 \mathrm{C}_{1} \mathrm{C}_{4} \mathrm{im}^{+}{ }_{(\mathrm{aq})}
$$

Under the chemical conditions of our experiments, the amount of $\mathrm{H}^{+}$and $\mathrm{Cl}^{-}$ions dissolved in the IL phase is known to be negligible, thus rendering ionic exchange through $\mathrm{H}^{+}$ impossible. ${ }^{56}$ The liquid-liquid extraction of trivalent rare earth ions by neutral calix $[n]$ arenes usually proceeds via formation of a complex ion pair of stoichiometry $1: 1$, metal : ligand in molecular solvents: $\left(\mathrm{CHCl}_{3}, 1,2\right.$-dichloroethane, nitrobenzene). ${ }^{31}$ The analysis of the extraction equilibrium obtained by Yaftian et al. ${ }^{33}$ from a mixture of four rare earths (La, Eu, Er and $\mathrm{Y})$ revealed that the extracted species $\left(\mathrm{ML}\left(\mathrm{NO}_{3}\right)_{3}\right.$, nitric acid solution $1 \mathrm{M}$ ) have also a 1 : 1 ratio for both (cone-1 and partialcone-1) ligands in 1,2-dichloroethane. However, it is seen that the distribution ratios of $\mathrm{La}(\mathrm{III})$ and $\mathrm{Eu}(\mathrm{III})$ decrease several times upon change of $\mathbf{S 1}$ with $\mathbf{S 2}$, Fig. $\mathbf{S} 27 \dagger$ so we did not perform a detailed study of the extraction mechanism with this compound. It is well-known that slight modifications in the nature and arrangement of the ligating groups affect enormously the interaction of an organic extractant with selected cations in molecular solvents ${ }^{32,33}$ and such effects have also been observed in ILs. ${ }^{57}$ It has been reported by Dung and Ludwig $^{58}$ that a much lower $\mathrm{Hg}$ (II) and $\mathrm{Pb}$ (II) extraction in toluene solutions was achieved in the presence of two $-\mathrm{CH}_{2} \mathrm{COOH}$ groups in comparison with the extractability of the corresponding calix[4]arene-based compound bearing four $\mathrm{CO}_{2} \mathrm{H}$ groups.

The chemical nature of the solvent usually has some significant importance on the extraction equilibria. ${ }^{3,31,33}$ The distribution ratios increase with the polarity of the organic phase. As a general rule, replacing a traditional molecular solvent by an IL leads to drastic enhancement effects on the distribution ratios, whatever the type of extracting agent (amine, phosphine oxide, etc). Usually, the advantage of IL compared with classical solvents is expressed as a lower concentration of the extracting moiety to be dissolved in the IL in order to obtain an identical $D$ value, with a concentration benefit in the range of a factor 4 to 30 (ref. 14 and 59) or even $500 .{ }^{60}$ Nakashima et al. ${ }^{59}$ also reported that the use of ILs greatly enhanced the extraction efficiency and selectivity of CMPO as an extractant for rare earth metals 
compared to $n$-dodecane used as the extracting solvent. For the specific case of calixarene based-extractants, similar enhancement effects have been observed: for example, Shimojo and Goto $^{19}$ reported that the extraction performance of pyridinocalix[4] arene towards silver ions was greatly enhanced by dissolution in ionic liquid (1-alkyl-3-methylimidazolium hexafluorophosphate) compared to chloroform.

Synergism HL-S1. Going from individual extractants to mixed systems, i.e. to the cooperative binding ability of two different extractants, the synergistic mixture HL-S1 shows a similar extraction model towards $\mathrm{La(III)}$ ions using $\left[\mathrm{C}_{1} \mathrm{C}_{4} \mathrm{im}\right]\left[\mathrm{Tf}_{2} \mathrm{~N}\right]$ and $\mathrm{CHCl}_{3}$ as solvents, as described by reaction (4). The $\log D$ values of La(III) using the IL phase with the HL-S1 mixture are plotted as a function of the aqueous phase $\mathrm{pH}$ and [HL] or [S] concentration. These plots are shown in Fig. 5. The overall equilibrium constant $K_{\mathrm{L}, \mathrm{S}}$ for $\mathrm{La}(\mathrm{III})$ obtained with the HL-S1 mixture using IL is approximately 2 orders of magnitude higher than that obtained using $\mathrm{CHCl}_{3}$ as a solvent. However, HL alone and $\mathbf{S 1}$ alone are already efficient extractants in ILs, and the overall synergism ability of the HL-S1 mixture in IL, although noticeable, is not as good in $\left[\mathrm{C}_{1} \mathrm{C}_{4} \mathrm{im}\right]\left[\mathrm{Tf}_{2} \mathrm{~N}\right]$ as it is in $\mathrm{CHCl}_{3}$ : the SC obtained in $\mathrm{CHCl}_{3}$ and in $\left[\mathrm{C}_{1} \mathrm{C}_{4} \mathrm{im}\right]\left[\mathrm{Tf}_{2} \mathrm{~N}\right]$ are 3.13 and 2.52 respectively. So, a moderate decrease of synergism is observed in IL for this system. Our result in this new system HL-S1/IL is in line with the work of Shimojo and co-workers, who observed that the combination of a crown-ether and an acidic extractant for $\mathrm{Sr}$ (II) extraction neither provides a better extraction in IL as compared to chloroform, nor offers significant synergism as compared to the individual extractants in the chosen IL, namely $\left[\mathrm{C}_{1} \mathrm{C}_{2} \mathrm{im}\right]\left[\mathrm{Tf}_{2} \mathrm{~N}\right] \cdot{ }^{60}$ Similarly, Hirayama et $a l .{ }^{16}$ showed that the addition of a crown-ether to HTTA in $\left[\mathrm{C}_{1} \mathrm{C}_{4} \mathrm{im}\right]\left[\mathrm{Tf}_{2} \mathrm{~N}\right]$ was of no help as regard synergism for $\mathrm{Lu}$ and $\mathrm{Eu}$.

It has been shown ${ }^{61}$ that synergism in molecular solvents using an acidic (HL) extractant in conjunction with a neutral (S) extractant, is due to the efficient complexation by $\mathrm{L}$, which allows formation of a neutral species to be dissolved in the molecular solvent, while $\mathrm{S}$ helps withdrawing the remaining water molecules from the metal coordination sphere, in order to further enhance the solubility in the molecular solvent. As demonstrated above, in $\left[\mathrm{C}_{1} \mathrm{C}_{4} \mathrm{im}\right]\left[\mathrm{Tf}_{2} \mathrm{~N}\right]$, for the mixtures $\mathbf{H L}-\mathbf{S 1}$ involvement of $3 \mathbf{H L}$ moieties is not enough to fulfill the 8 or 9 lanthanide coordination sphere requirement that we have evidenced in various IL phases. ${ }^{62,63}$ In this respect, the situation appears to be quite similar in $\mathrm{CHCl}_{3}$ and IL. However, $\left[\mathrm{C}_{1} \mathrm{C}_{4} \mathrm{im}\right]\left[\mathrm{Tf}_{2} \mathrm{~N}\right]$ does tolerate large amounts of water in its bulk, ${ }^{56}$ and highly or fully hydrated lanthanoid ions easily dissolve in this IL. ${ }^{64}$ As a consequence, the presence of S1 does not appear as mandatory as it is in chloroform to improve extraction efficiency. This is in line with the involvement of only three HL moieties in the absence of S1: there is in fact no absolute need for a water-free coordination sphere to get high extraction distribution ratio when using $\left[\mathrm{C}_{1} \mathrm{C}_{4} \mathrm{im}\right]\left[\mathrm{Tf}_{2} \mathrm{~N}\right]$. In other words, the limited synergistic effect observed in $\left[\mathrm{C}_{1} \mathrm{C}_{4} \mathrm{im}\right]\left[\mathrm{Tf}_{2} \mathrm{~N}\right]$ is in line with the observation made in several molecular solvents that an increase in water solubility leads to a decrease in synergism. ${ }^{61}$

Selectivity across the Ln series in IL. To assess the possibility to separate $\mathrm{La}$ over $\mathrm{Eu}$ as well as to know the selectivity performance of the corresponding systems in $\left[\mathrm{C}_{1} \mathrm{C}_{4} \mathrm{im}\right]\left[\mathrm{Tf}_{2} \mathrm{~N}\right]$, the separation factors between La and Eu defined as the ratio of the respective distribution ratios (Fig. S27 $\dagger$ ) were calculated and depicted in Table 4.

Concerning the SF values obtained with $\mathbf{H L}$, the value in chloroform is much higher than in $\left[\mathrm{C}_{1} \mathrm{C}_{4} \mathrm{im}\right]\left[\mathrm{Tf}_{2} \mathrm{~N}\right]$. In the case of the synergistic mixtures $\mathbf{H L}-\mathbf{S} 1$ or $\mathbf{H L}-\mathbf{S 2}$, a striking detrimental effect of the IL is seen, as SF values are drastically

Table 4 Values of separation factors of Eu/La pair obtained with different systems

\begin{tabular}{llllrl}
\hline Systems & Eu/La & Solvent & Systems & Eu/La & Solvent \\
\hline HL & 2.4 & IL & HL-S2 & 1.0 & IL \\
S1 & 0.4 & IL & HL & 5.8 & $\mathrm{CHCl}_{3}$ \\
S2 & 1.2 & IL & HL-S1 & 20.8 & $\mathrm{CHCl}_{3}$ \\
HL-S1 & 1.4 & IL & HL-S2 & 18.2 & $\mathrm{CHCl}_{3}$
\end{tabular}
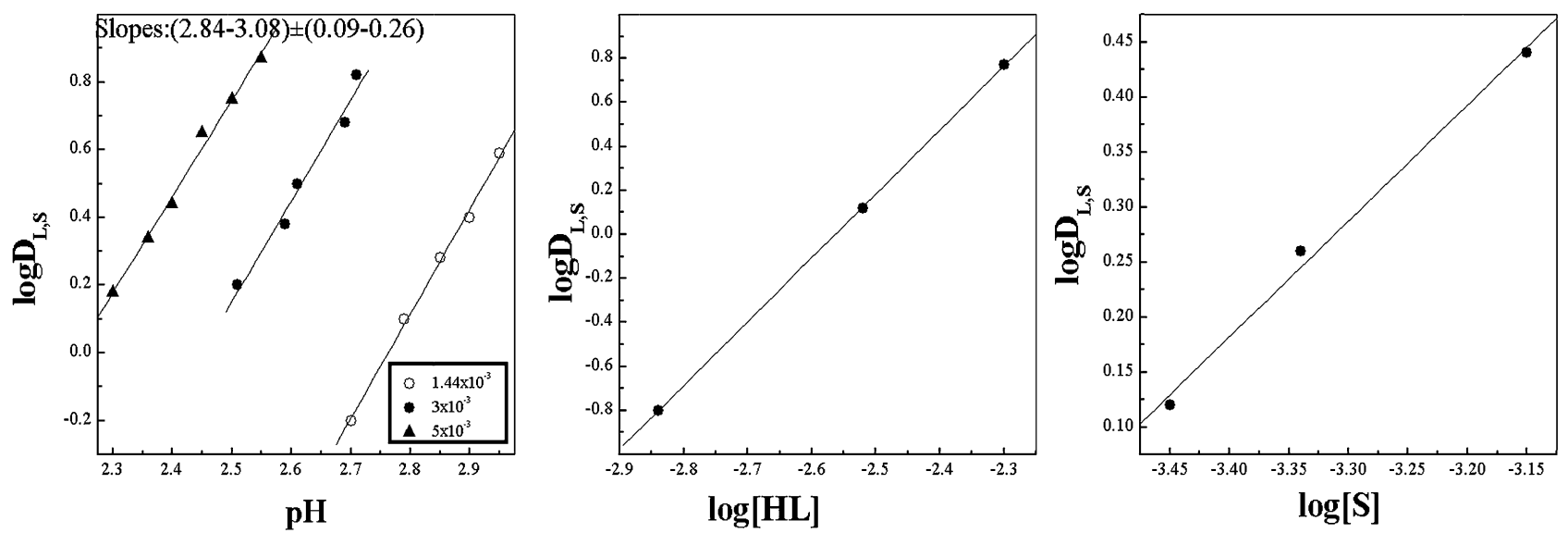

Fig. $5 \log D_{\mathrm{L}, \mathrm{S}}$ vs. $\mathrm{pH}$ for La(III) extraction with $\mathrm{HL}-\mathrm{S} 1$ at $[\mathrm{S}]=7 \times 10^{-4} \mathrm{~mol} \mathrm{dm}{ }^{-3}$ in IL. $\log D_{\mathrm{L}, \mathrm{S}}$ vs. log[HL] (3 concentrations) for La(III) ion extraction at $[\mathrm{S}]=7 \times 10^{-4} \mathrm{~mol} \mathrm{dm}{ }^{-3}$ and $\mathrm{pH}=2.50$, slope $0.98 \pm 0.06 . \log D_{\mathrm{L}, \mathrm{S}} v \mathrm{~s}$. $\log [\mathrm{S}](3$ concentrations) for La(III) ion extraction at $[\mathrm{HL}]=3 \times$ $10^{-3} \mathrm{~mol} \mathrm{dm}^{-3}$ and $\mathrm{pH}=2.60$, slope $1.04 \pm 0.12$. 
decreased in this solvent, being now close to one, indicating an almost negligible separation efficiency and an unfavorable effect of mixing extractant in view of selective extraction in $\left[\mathrm{C}_{1} \mathrm{C}_{4} \mathrm{im}\right]\left[\mathrm{Tf}_{2} \mathrm{~N}\right]$. ILs dramatically increase extraction abilities, being very good at enhancing extraction performances of any compound but, by doing so, they logically tend to level off separation factors. This can be put in parallel with the leveling off of complexation abilities of inorganic ligands towards metallic cations as already observed and discussed. ${ }^{65}$

\section{Conclusions}

The extraction of a chelating extractant 3-methyl-1-phenyl-4-(4trifluoromethylbenzoyl)-pyrazol-5-one (HL) in the presence of partially phosphorylated at the narrow rim calix[4]arenes (S) as synergistic agents towards five $\mathrm{Ln}(\mathrm{III})$-ions was studied in $\mathrm{CHCl}_{3}$. The composition of the extracted species was established as $\mathrm{LnL}_{3} \cdot \mathbf{H L}$ and $\mathrm{LnL}_{3} \cdot \mathrm{S}$. The NMR investigations on the interaction between the extractants showed that the $\mathrm{P}=\mathrm{O}$ groups of $\mathrm{S}$ form moderate $\mathrm{H}$-bonds with pyrazolone hydroxyl function in chloroform solutions. The addition of the phosphorus-containing $p$ tert-butylcalix[4]arenes produces large synergistic effect up to $10^{3}$ and improves the selectivity among the lighter lanthanoid ions in comparison with HL alone. The best results regarding extractive efficacy were obtained with the tris-phosphorylated compound. $\mathrm{La}$ (III) and $\mathrm{Eu}(\mathrm{III})$ ions were efficiently extracted using different compound systems in ionic liquid under conditions comparable as those in chloroform. The NMR experiments showed that no interactions occur between IL and HL independently on the solvent nature: benzene, acetonitrile and chloroform.

As a general rule, our results indicate that this "green media" has fantastic extraction potential which results in less selectivity. As a consequence, ILs appear to be of limited interest for the effective individual separation of lanthanoids from an aqueous mixture arising from dissolution of industrial scraps or end-of-cycle processes although they could provide very high extraction distribution ratios. However, separating each Ln from such mixtures to mix them again to obtain new magnets, for example, may appear quite inefficient and it might be better to recover all Ln taken as a mixture, separated from d-metals. ${ }^{66}$ In this perspective, the levelling off of separation factors as obtained in ILs, at values around 1 by use of "ineffective synergistic mixtures", together with the very high distribution ratios, would be an interesting property of such solvents.

\section{Acknowledgements}

The financial support by the Bulgarian Science Fund projects UNA-17/2005 and DRNF-02-13/2009 is gratefully acknowledged. The authors are also grateful to FP7-PEOPLE-Marie Curie Actions-IEF for the support of the project INNOVILLN (622906) 2014-2016, to which this work is fully related.

\section{Notes and references}

1 M. Atanassova, V. Kurteva, L. Lubenov, S. Varbanov and I. Dukov, Sep. Purif. Technol., 2012, 95, 58.
2 M. Atanassova, V. Lachkova, N. Vassilev, S. Varbanov and I. Dukov, Polyhedron, 2010, 29, 655.

3 M. A. Petrova, V. I. Lachkova, N. G. Vassilev and S. Varbanov, Ind. Eng. Chem. Res., 2010, 496, 189.

4 M. Atanassova, V. Lachkova, N. Vassilev, S. Varbanov and I. Dukov, J. Inclusion Phenom. Macrocyclic Chem., 2007, 58, 173.

5 M. Atanassova, N. Vassilev and I. Dukov, Sep. Purif. Technol., 2011, 78, 214.

6 M. Atanassova, Microchim. Acta, 2011, 174, 175.

7 M. Petrova, V. Kurteva and L. Lubenov, Ind. Eng. Chem. Res., 2011, 50, 12170.

8 M. Atanassova, V. Lachkova, N. Vassilev, B. Shivachev, S. Varbanov and I. Dukov, Polyhedron, 2008, 27, 3306.

9 A. Stojanovic and B. K. Keppler, Sep. Sci. Technol., 2012, 47, 189.

10 K. Binnemans, Chem. Rev., 2007, 107, 2592.

11 I. Billard, Ionic liquids: new hopes for efficient lanthanide/ actinide extraction and separation, in Handbook on the Physics and Chemistry of Rare Earths, ed. J. C. G. Bünzli and V. Pecharsky, Elsevier Science Publ. B. V., Amsterdam, 2013, ch. 256, vol. 43, pp. 213-273.

12 I. Billard and C. Gaillard, Radiochim. Acta, 2009, 97, 355.

13 I. Billard, A. Ouadi and C. Gaillard, Dalton Trans., 2013, 42, 6203.

14 A. Rout, A. Venkatesan, V. Srinivasan and V. R. Rao, Radiochim. Acta, 2009, 97, 719.

15 K. Shimojo, H. Okamura and N. Hirayama, Dalton Trans., 2009, 4850.

16 N. Hirayama, H. Okamura, K. Kindani and H. Imura, Anal. Sci., 2008, 24, 697.

17 D. Stepinski, M. Jensen, J. Dzielawa and M. Dietz, Green Chem., 2005, 17, 151.

18 C. Xu, L. Yuan, X. Shen and M. Zhai, Dalton Trans., 2010, 39, 3897.

19 K. Shimojo and M. Goto, Anal. Chem., 2004, 76, 5039.

20 C. Pettinari, F. Marchetti and A. Drozdov, $\beta$-Diketones and related ligands in Comprehensive Coordination Chemistry II, ed. J. A. McCleverty and T. J. Meye, Elsevier, 2003, ch. 1.6, vol. 1, pp. 97-115.

21 R. Meera and M. L. P. Reddy, Solvent Extr. Ion Exch., 2004, 22, 761.

22 K. Binnemans, Rare earth beta-diketones, Handbook on the physics and chemistry of rare earths, ed. K. A. Gschneider, J.C. G. Bünzli and V. K. Pecharsky, Elsevier, 2005, ch. 225, vol. 35, pp. 107-272.

23 H. Mukai, S. Miyazaki, S. Umetani, S. Kihara and M. Matsui, Anal. Chim. Acta, 1990, 239, 277.

24 F. Arnaud-Neu, M.-J. Schwing-Weil and J. F. Dozol, Calixarenes for nuclear waste treatment, in Calixarenes, ed. Z. Asfari, V. Böhmer, J. Harrowfield and J. Vincens, Kluwer, Dortrecht, 2001, ch. 35, pp. 642-661.

25 B. Creave, D. Donlon and J. McGinley, Coord. Chem. Rev., 2009, 253, 893.

26 S. Alexandratos and S. Natesan, Ind. Eng. Chem. Res., 2000, 39, 3998. 
27 F. Arnaud-Neu, S. Barboso, S. Fanni, M.-J. Schwing-Weill, V. McKee and M. McKervey, Ind. Eng. Chem. Res., 2000, 39, 3489.

28 A. Kaya, H. Alpoguz and A. Yilmaz, Ind. Eng. Chem. Res., 2013, 52, 5428.

29 V. Jain, S. Pillai, R. Pandya, Y. Agrawal and P. Shrivastav, Talanta, 2005, 65, 466.

30 F. Arnaud-Neu, S. Barbaso, V. Böhmer, F. Brisach, L. Delmau, S. F. Dozol, O. Mogck, E. Paulus, M. Saadioui and A. Shivanyuk, Aust. J. Chem., 2003, 56, 1113.

31 M. Yaftian, M. Burgard, D. Matt, C. Dieleman and F. Rastegar, Solvent Extr. Ion Exch., 1997, 15, 975.

32 R. Ludwig, D. Lentz and T. Nguyen, Radiochim. Acta, 2000, 88, 335 .

33 M. Yaftian, M. Burgard, C. Wieser, C. Dieleman and D. Matt, Solvent Extr. Ion Exch., 1998, 16, 1131.

34 W. He, W. Liao, C. Niu and D. Li, Sep. Purif. Technol., 2008, $62,674$.

35 H.-J. Chuang, H.-L. Chen, J.-L. Ye, Z.-Y. Chen, P.-L. Huang, T.-T. Liao, T.-E. Tsai and C.-C. Lin, J. Polym. Sci., Part A: Polym. Chem., 2013, 51, 696.

36 B. S. Jensen, Acta Chem. Scand., 1959, 13, 1668.

37 V. Kurteva, S. Varbanov and W. Frank, Supramol. Chem., 2006, 18, 621.

38 S. B. Savvin, Arsenazo III, Atomizdat, Moskva, 1966, p. 177.

39 J. N. Mathur and P. K. Khopkar, Polyhedron, 1987, 6, 2099.

40 E. Halpern, J. Bouck, H. Finegold and J. Goldenson, J. Am. Chem. Soc., 1955, 77, 4472.

41 M. W. Hanson and J. B. Bouck, J. Am. Chem. Soc., 1957, 79, 5631.

42 A. Zhang, Solvent Extr. Ion Exch., 2001, 19, 925.

43 Y. Marcus and A. S. Kertes, Ion exchange and solvent extraction of metal complexes, Willey Interscience, New York, 1969, pp. 815-858.

44 Y. Zuo, Y. Liu and D. Li, Ind. Eng. Chem. Res., 2008, 47, 2349.

45 K. V. Lohithakshan and S. K. Aggarwal, Radiochim. Acta, 2008, 96, 93.

46 A. Rout, K. A. Venkatesan, T. G. Srinivasan and P. R. Vasudeva Rao, Radiochim. Acta, 2010, 98, 459.
47 N. Papaiconomou, G. Vite, N. Goujon, J. M. Lévêque and I. Billard, Green Chem., 2012, 14, 2050.

48 T. Vander Hoogerstraete, B. Onghena and K. Binnemans, J. Phys. Chem. Lett., 2013, 4, 1659.

49 M. Sypula, A. Ouadi, C. Gaillard and I. Billard, RSC Adv., 2013, 3, 10736.

50 F. Yang, F. Kubota, N. Kamiya and M. Goto, Solvent Extr. Res. Dev., Jpn., 2013, 20, 225.

51 V. A. Cocalia, M. P. Jensen, J. D. Holbrey, S. K. Spear, D. C. Stepinski and R. D. Rogers, Dalton Trans., 2005, 1966.

52 A. Chaumount and G. Wipff, Inorg. Chem., 2004, 43, 5891.

53 Y. Albinsson, Acta Chem. Scand., 1989, 43, 919.

54 Y. Albinsson, A. Mahmood, M. Majdan and J. Rydberg, Radiochim. Acta, 1989, 48, 49.

55 M. E. Mincher, D. L. Quach, Y. J. Liao, B. J. Mincher and C. M. Wai, Solvent Extr. Ion Exch., 2012, 30, 735.

56 C. Gaillard, V. Mazan, S. Georg, O. Klimchuk, M. Sypula, I. Billard, R. Schurhammer and G. Wipff, Phys. Chem. Chem. Phys., 2012, 14, 5187.

57 A. Ouadi, O. Klimchuk, C. Gaillard and I. Billard, Green Chem., 2007, 9, 1160.

58 N. Dung and R. Ludwig, New J. Chem., 1999, 23, 603.

59 K. Nakashima, F. Kubotra, T. Maruyama and M. Goto, Ind. Eng. Chem. Res., 2005, 44, 4368.

60 K. Shimojo, H. Okamura, N. Hirayama, S. Umetani, H. Imura and H. Naganawa, Dalton Trans., 2009, 4850.

61 G. R. Choppin and A. Morgenstern, Solvent Extr. Ion Exch., 2000, 18, 1029.

62 I. Billard and C. Gaillard, Radiochim. Acta, 2009, 97, 355.

63 C. Gaillard, I. Billard, A. Chaumont, S. Mekki, A. Ouadi, M. Denecke, G. Moutiers and G. Wipff, Inorg. Chem., 2005, 44, 8355.

64 I. Billard, S. Mekki, C. Gaillard, P. Hesemann, G. Moutiers, C. Mariet, A. Labet and J. C. G. Bünzli, Eur. J. Inorg. Chem., 2004, 1190.

65 A. Chaumont, O. Klimchuk, C. Gaillard, I. Billard, A. Ouadi, C. Hennig and G. Wipff, J. Phys. Chem. B, 2012, 116, 3205.

66 T. Vander Hoogerstraete, S. Wellens, K. Verachtert and K. Binnemans, Green Chem., 2013, 15, 919. 